\title{
Examining Plasmodium falciparum and $P$. vivax clearance subsequent to antimalarial drug treatment in the Myanmar-China border area based on quantitative real-time polymerase chain reaction
}

Eugenia Lo ${ }^{1}$, Jennifer Nguyen ${ }^{1}$, Winny Oo ${ }^{1}$, Elizabeth Hemming-Schroeder ${ }^{1}$, Guofa Zhou ${ }^{1}$, Zhaoging Yang ${ }^{2}$, Liwang Cui ${ }^{3}$ and Guiyun Yan ${ }^{{ }^{*}}$

\begin{abstract}
Background: Recent emergence of artemisinin-resistant $P$. falciparum has posed a serious hindrance to the elimination of malaria in the Greater Mekong Subregion. Parasite clearance time, a measure of change in peripheral parasitaemia in a sequence of samples taken after treatment, can be used to reflect the susceptibility of parasites or the efficiency of antimalarials. The association of genetic polymorphisms and artemisinin resistance has been documented. This study aims to examine clearance time of $P$. falciparum and P. vivax parasitemia as well as putative gene mutations associated with residual or recurred parasitemia in Myanmar.
\end{abstract}

Methods: A total of 63 P. falciparum and 130 P. vivax samples collected from two internally-displaced populations and one surrounding village were examined for parasitemia changes. At least four samples were taken from each patient, at the first day of diagnosis up to 3 months following the initial treatment. The amount of parasite gene copy number was estimated using quantitative real-time PCR based on a species-specific region of the $18 \mathrm{~S}$ rRNA gene. For samples that showed residual or recurred parasitemia after treatment, microsatellites were used to identify the 'post-treatment' parasite genotype and compared such with the 'pre-treatment' genotype. Mutations in genes pfcrt, pfmdr1, pfatp6, pfmrp 1 and pfK13 that are potentially associated with ACT resistance were examined to identify if mutation is a factor for residual or persistent parasitemia.

Results: Over $30 \%$ of the $P$. falciprium infections showed delayed clearance of parasitemia after 2-3 days of treatment and $9.5 \%$ showed recurred parasitemia. Mutations in codon 876 of the pfmrp 1 corroborated significance association with slow clearance time. However, no association was observed in the variation in pfmdr1 gene copy number as well as mutations of various codonsinpfatp6, pfcrt, and pfK 13 with clearance time. For P. vivax, over $95 \%$ of the infections indicated cleared parasitemia at days 2-3 of treatment. Four samples were found to be re-infected with new parasite strains based on microsatellite genotypes after initial treatment.

Conclusion: The appearance of P.falciparum infected samples showing delayed clearance or recurred parasitemia after treatment raises concerns on current treatment and ACT drug resistance.

Keywords: P. falciparum, P. vivax, Malaria, Artemisinin-combined therapy, Quantitative PCR, Parasite clearance, Resistance genes, Microsatellite

\footnotetext{
* Correspondence: guiyuny@uci.edu

${ }^{1}$ Program in Public Health, University of California at Irvine, Irvine, CA

92697-4050, USA

Full list of author information is available at the end of the article
} 


\section{Background}

Internal conflict and associated large-scale human movement in Myanmar during the past few years have in part attributed to an increase of malaria cases within the country and to its spread beyond the national border into Thailand and China [1]. Along with the high malaria burden, multidrug-resistant Plasmodium falciparum malaria has also emerged and widespread in endemic areas of the Greater Mekong Subregion (GMS) [1]. In the 1960s and 1970s, chloroquine (CQ) resistance had spread throughout the region and subsequently, in the 1980s, resistance to sulphadoxine and pyrimethamine (SP) was reported [2]. Nevertheless, SP combination is still the drug treatment recommended by WHO for intermittent preventive treatment (IPT) in vulnerable populations because of its safety in pregnant women and infants and its long-lasting action. Following the decline in clinical efficacy of CQ and SP, the artemisinin-based combination therapy (ACT) using the artesunatemefloquine combination was introduced as first-line treatment in the 1990s [3]. However, the recent emergence of artemisinin-resistant $P$. falciparum in the GMS has posed a serious hindrance to the elimination of malaria [4]. The reduced susceptibility to ACT may have also spread to the African continent where some of the affected countries have adopted ACT as first-line antimalarial treatment [5].

Parasite Clearance Time (PCT), a measure of change in peripheral parasitaemia in a sequence of samples taken after treatment, can be used to reflect the susceptibility of parasites or the efficiency of antimalarials. Typically, malaria parasite densities are expected to be reduced by a factor of $10^{8}$ after a 3-day treatment course with an ACT, with $95 \%$ of patients' microscopic results to be negative $48 \mathrm{~h}$ after treatment [6]. However, contrary to this expectation, an increasing number of cases of delayed parasite clearance after treatment with an artemisinin derivative have been reported in Cambodia [7-9]. Along the Thailand-Cambodia border, the time to reach the clearance of parasites after artesunatemefloquine combination therapy has also become longer $[10,11]$. In Kenya, over $30 \%$ of children were reported with residual submicroscopic parasitemia after ACT [5]. These children were significantly more likely to experience recurrent parasitemia during follow-up. Parasite clearance time is influenced by parasite drug susceptibility, parasite density before initiation of treatment, and inter-individual differences in antimalarial pharmacokinetics and immunity [12]. A recent study with clonally identical parasites has shown that clearance time was primarily dictated by the parasite's genetic background and less by host factors, which allows the identification of these parasite factors through genome-wide association [13].
The genetic basis of resistance to antimalarials, such as chloroquine (CQ) and sulfdoxine/pyrimethamine (SP), has been well documented. Numerous molecular studies have indicated multiple independent origins of CQ resistance associated with mutations in the chloroquine-resistance transporter gene $(c r t)$ [14-16], and the multidrug resistance transporter gene $(m d r 1)$ [17-19], as well as SP resistance associated with mutations in the genes encoding dihydrofolate reductase ( $d h f r$ ) and dihydropteroate synthase (dhps) in P. falciparum [20-23]. However, for other antimalarials such as ACT, the molecular mechanism of resistance still remains unclear. Previous studies have shown the association of several mutations with moderately altered susceptibility to one or more artemisinin derivatives. For example, mutations in gene $p f m r p 1$ were likely associated with resistance to $C Q$, mefloquine (MQ), and artemisinin derivatives [24, 25]. Likewise, Gupta et al. [25] indicated signature of positive selection in pfmrp 1 that was associated with reduced susceptibilities to CQ, $\mathrm{MQ}$, pyronaridine, and lumefantrine in the northeast Myanmar $P$. falciparum isolates. Other studies have shown that changes in amino acids 263 and 769 of the $p$ fatp6 gene were related to reduced in vitro artemisinin inhibition [26-28], but no variations were detected in these positions among natural falciparum populations [29, 30]. Recently, a strong association was detected between mutations in $p f m d r 1$ gene and reduced susceptibility of $P$. falciparum isolates to $\mathrm{MQ}$, artesunate, and quinine in areas along the Thai-Cambodian and Thai-Myanmar borders $[18,30]$. Furthermore, several mutations in thepfK13-propeller gene (K13), PF3D7_1343700, have been reported in the China-Myanmar border area, and those mutations may associate with artemisinin resistance [31].

In Myanmar, reduced susceptibilities to ACT have been continuously reported [32-34]. Detailed monitoring of parasite clearance dynamics after antimalarial treatment is needed to determine whether parasite responsiveness to $\mathrm{ACT}$ is changing. For such purposes, quantitative polymerase chain reaction (qPCR) method has been proposed for the analysis of sequentially collected daily filter paper blood samples after initiation of treatment to sensitively detect and quantify parasites below the microscopic threshold [35]. In this study, we aimed to first measure parasitemia level of Plasmodium falciparum and P. vivax infections detected in Internally Displaced Population (IDP) settlement and surrounding villages of Myanmar over duration of 42 days or longer after initial drug treatment; second, to identity the proportion of individuals with residual/persistent parasitemia or with recurring infections. We then asked whether the recurring infections were attributed to the same or different parasite strain. Third, we compared sequences of a panel of antimalarial drug resistance genes between infections of fast and delayed clearance to examine the associated mutations. 


\section{Methods}

\section{Sample collection}

Nearly 100 patients diagnosed with $P$. falciparum and $P$. vivax infections were included in this study. These individuals were selected from clinics/hospitals located in the IDP settlement (Je Yang Hka) and surrounding village (Laiza) in Myanmar from 2011 to 2013. All studied individuals showed fever or malaria-related symptoms at the first day of diagnosis. They were diagnosed with falciparum and/or vivax infection by microscopic examination and later confirmed by PCR assays. Patients diagnosed with uncomplicated $P$. falciparum malaria were treated with dihydroartemisinin-piperaquine (DP) and those with $P$. vivax malaria were treated with chloroquine (CQ). For each patient, at least four samples were taken from day 0 (before antimalarial treatment) and then at days $1,2,3,7,14,28,42$, and up to 3 months after beginning of treatment. All samples of each of the patients were run in parallel to estimate the level of parasitemia during treatment. For each sample, 30-50 $\mu \mathrm{l}$ of blood was blotted onto Whatman 3MM filter papers. Filter papers were air-dried and stored in zip-sealed plastic bags with silica gel absorbent at room temperature until DNA extraction. Parasite DNA was extracted from dried blood spots by the Saponin/Chelex method [36]. Samples that showed cleared parasites on day 2 or 3 were classified as fast clearance, whereas those that showed cleared parasites after day 3 of the initial drug treatment were classified as delayed clearance [37-39]. In addition, we calculated parasite reduction ratio after the first $48 \mathrm{~h}$ of antimalarial treatment $\left(\mathrm{PRR}_{48}\right)$ as follow: (parasitemia after $48 \mathrm{~h}$ of treatment)/(initial parasitemia) [40-42]. We used a PRR value of 0.01 as cut-off, i.e. $99 \%$ of the initial parasitemia cleared after $48 \mathrm{~h}$ of drug treatment and compared the results between samples of fast and delayed clearance.

\section{Quantification of parasitemia by real-time qPCR assays} Quantitative real-time PCR specifically the SYBR Green detection method [43] was employed using P. falciparum-specific primers (forward: 5'AGTCATCTTTC GAGGTGACTTTTAGATTGCT-3'; reverse: 5'- GCC GCAAGCTCCACGCCTGGTGGTGC-3') and $P$. vivaxspecific primers (forward: 5'-GAATTTTCTCTTCGGA GTTTATTCTTAGATTGC-3'; reverse: 5'GCCGCAAG CTCCACGCCTGGTGGTGC-3') that targeted on the plasmodial 18S rRNA region [43]. Amplification was conducted in a $20 \mu \mathrm{l}$ reaction mixture containing $2 \mu \mathrm{l}$ of genomic DNA, $10 \mu \mathrm{l}$ of $2 \times$ SYBR Green qPCR Master Mix (Thermo Scientific), and $0.5 \mu \mathrm{M}$ primer. Reaction was performed in CFX96 Touch $^{\text {тм }}$ Real-Time PCR Detection System (BIORAD), with an initial denaturation at $95{ }^{\circ} \mathrm{C}$ for $3 \mathrm{~min}$, followed by 45 cycles at $94{ }^{\circ} \mathrm{C}$ for $30 \mathrm{~s}, 55^{\circ} \mathrm{C}$ for $30 \mathrm{~s}$, and $68{ }^{\circ} \mathrm{C}$ for $1 \mathrm{~min}$ with a final
$95{ }^{\circ} \mathrm{C}$ for $10 \mathrm{~s}$. This was then followed by a melting curve step of temperature ranging from $65{ }^{\circ} \mathrm{C}$ to $95{ }^{\circ} \mathrm{C}$ with $0.5{ }^{\circ} \mathrm{C}$ increments to determine the melting temperature of each amplified product. Each assay included positive controls of both $P$. falciparum7G8 (MRA-926) and HB3 (MRA-155) isolates as well as $P$. vivax Pakchong (MRA-342G) and Nicaragua (MRA$340 \mathrm{~g}$ ) isolates, in addition to negative controls including uninfected samples and water. A standard curve was produced from 10-fold dilution series of the control plasmids ( $P$. falciparum and $P$. vivax) and laboratory culture ( $P$. falciparum) ranging from $1 \%$ to $1.75 \times 10^{-12} \%$ to evaluate $\mathrm{qPCR}$ efficiency as well as to extrapolate parasite density from gene copies. Melting curve analyses were performed for each amplified sample to confirm specific amplifications of the target sequence. The slope of the linear regression of threshold cycle number $\left(C_{t}\right)$ versus $\log _{10}$ (Gene Copy Number) was used to calculate amplification efficiency (E). The amplification efficiency ranges from $92 \pm 2 \%$ among all runs. For the measure of reproducibility of the threshold cycle number $\left(C_{t}\right)$, the mean $C_{t}$ value was calculated from triplicates in two independent assays. A cutoff threshold of 0.02 fluorescence units that robustly represented the threshold cycle at the loglinear phase of the amplification and above the background noise was set to determine $C_{t}$ value for each sample. Samples yielding $C_{t}$ values higher than 40 (as indicated in the negative controls) were considered negative for Plasmodium species. The parasite gene copy number $(\mathrm{GCN})$ in a sample was quantified based on the threshold cycle using the follow equation: $\left.\mathrm{GCN}_{\text {sample }}=\mathrm{e}^{[\mathrm{E} \times \Delta C \text { tsample }}\right]$; where $\mathrm{GCN}$ stands for gene copy number, $\Delta C_{t}$ for the difference in threshold cycle between the negative control and the sample, and $\mathrm{E}$ for amplification efficiency.

\section{Microsatellite genotyping}

For patients who showed residual or recurred parasitemia after treatment, multilocus genotypes based on microsatellites were compared between samples collected at day 0 (before treatment) and the day that indicated recurred parasitemia subsequent to treatment. Thirteen single-copy microsatellites with tri- or tetranucleotide repeats, which mapped to 14 chromosomes, were typed for P. falciparum. Alleles were PCR-amplified with the published oligonucleotide primers $[44,45]$. For each PCR reaction, $2 \mu \mathrm{l}$ of genomic DNA were used with $2 \mathrm{mM} \mathrm{MgCl}_{2}, 2 \mu \mathrm{M}$ of each primer, $0.1 \mathrm{mM}$ of each $\mathrm{dNTP}, 1 \mathrm{U}$ of recombinant Taq polymerase, and $10 \mu \mathrm{l}$ of $2 \times$ Taq polymerase buffer in a final volume of $20 \mu \mathrm{l}$. All reagents were purchased from Thermo-Scientific, except for primers (both labeledwith fluorescent dyes and unlabeled), which were supplied by 
Applied Biosystems (Foster City, CA). PCR cycling conditions were as follow: $2 \mathrm{~min}, 94{ }^{\circ} \mathrm{C}$; $\left(30 \mathrm{~s}, 94{ }^{\circ} \mathrm{C}\right.$; $40 \mathrm{~s}, 58{ }^{\circ} \mathrm{C}$; $50 \mathrm{~s}, 72{ }^{\circ} \mathrm{C}$ ) for 40 cycles; $5 \mathrm{~min}, 72^{\circ} \mathrm{C}$. After PCR amplification, products were pooled as follows: TAA87 + PFPK2 + POLY2 + 9735, TA1 + TAA42 + TA81 + TA109, PE87a + PfG377 POLY $\alpha+$ TA124, TA80 + TA116 according to their sizes and fluorescent labels. All alleles were determined and visualized in Peak Scanner. The identity or differences in genotypes allowed us to determine whether recurred parasitemia was attributed to the same or new parasite strain(s) after treatment.

\section{Resistance gene sequencing of $P$. falciparum}

To examine the association between resistance gene mutations and parasitemia clearance time, five gene regions ( $p f c r t, p f m d r 1, p f a t p 6$, and pfmrp1, and pfK13) that are putatively associated with ACT resistance, were sequenced with $P$. falciparum day 0 samples (before antimalarial treatment). Polymorphisms were examined for the following codons of each respective gene: pfcrt gene codon76; pfindr1- codons 86, 184, 1034, 1042, and 1246; pfatp6- codons 37, 89, 693, 769; pfmrp1- codons 191, 437,866, 876, 1390 and 1466; pfK13 - codon446 (of which mutant was shown to be prevalent in Myanmar) [31, 32]. Amplification was conducted in a $20 \mu$ reaction mixture containing $3 \mu \mathrm{l}$ of genomic DNA, $12.5 \mu \mathrm{l}$ of $2 \times$ DreamTaq Green PCR Master Mix (Thermo Scientific, Waltham, MA), and $10 \mathrm{nmol}$ of forward and reverse primes. We used the primers as well as the PCR conditions of the published protocols [31, 46-50]. PCR products were then purified the by the SAP-ExoI method (Affymetrix, Santa Clara, CA) and sequenced in both directions by Sanger sequencing (GENEWIZ).

\section{Pfmdr1 gene copy estimation}

The $p f m d r 1$ gene copy number of $P$. falciparum day 0 samples were assessed by real-time PCR. Genomic DNA of P. falciparum clones 3D7 (which has a single copy of pfmdr1) was used as a calibrator and pfß-tubulin, a house-keeping gene, was used as an internal control. The primers for the amplifications of $p f m d r 1$ and $\beta$-tubulin were described previously [51]. Amplification was performed in triplicate in a total volume of $20 \mu \mathrm{l}$ containing $10 \mu$ lof SYBR Green PCR Master Mix, $0.75 \mu \mathrm{l}$ of each of the sense and anti-sense primers $(10 \mu \mathrm{M}), 20 \mathrm{ng}$ of genomic DNA and $3.5 \mu$ l of water. PCR condition was as follow: $95{ }^{\circ} \mathrm{C}$ for $10 \mathrm{~min}$, followed by 40 cycles at $95{ }^{\circ} \mathrm{C}$ for $15 \mathrm{~s}$ and at $60^{\circ} \mathrm{C}$ for $1 \mathrm{~min}$. A negative control with no template was used in each run. Each sample was run in triplicates and the $C_{t}$ values and melting temperature were recorded at the end of the reactions. The average and standard deviation of the three $C_{t}$ values were calculated, and the average value was accepted if the SD was lower than 0.32 . In this study, the $2^{-\Delta \Delta C t}$ method for relative quantification [52] was used to estimate the copy numbers of $p f m d r 1$ gene by the following equation: ${ }^{\Delta \Delta} C_{t}=\left(C_{t \text { target gene }}-C_{t p f b-t u b u l i n}\right)_{\text {unknown sample }}{ }^{-}$ $\left(C_{t \text { target gene }}-C_{t p f b \text {-tubulin }}\right)_{3 \mathrm{D} 7}$. The result for each sample was expressed in $\mathrm{N}$-fold changes in unknown samples $\left(2^{-\Delta \Delta \mathrm{Ct}}\right)$. A minimum of two independent runs was conducted for each sample and the results were expressed as the $\mathrm{N}$-fold copy number of a given gene relative to P. falciparum 3D7 by calculating the mean between the two runs. $\mathrm{N}$-fold copy numberbetween 0.8 and 1.4 was considered as a single copy and $\mathrm{N}$-fold copy number greater than 1.5 was considered as multiple copies of the target gene $[52,53]$.

\section{Statistical analyses}

Ordered logistic regression, both univariate and multiple, was used to analyze the association between clearance time and resistance gene mutations. The following combination of orders of parasite clearance time were tested: i) parasite cleared within 3 days (order 1), 7 days (order 2), 14 days (order 3), not cleared (order 4); ii) parasite cleared within 3 days (order 1), 7-14 days (order 2), not cleared (order 3); iii) parasite cleared within 3 days (order 1), 7 days (order 2), 14 days or not cleared (order 3); iv) parasite cleared within 3 days (order 1) and the rest (order 2). In addition, Fisher's exact test (given small sample size) was used to test for significant differences in age (below and above 18) and initial parasitemia between samples that showed fast and delayed parasite clearance time. All statistical analyses were performed in R ( $\mathrm{R}$ Core Team 2013).

\section{Results}

Change in parasitemia after initial drug treatment

For the 130 patients who were diagnosed with $P$. vivax, 124 (95.4 \%) showed cleared parasitemia at days 2 or 3 . These samples indicated a $\mathrm{PRR}_{48}$ value of $<0.01$, which means over $99 \%$ of the initial parasitemia was cleared after $48 \mathrm{~h}$ of treatment. Only two samples (1.5 \%) showed delayed clearance where residual parasitemia remained at day 3 but cleared at day 7 (Table 1; Fig. 1). Four of the samples indicated initial decline but recurred parasitemia at day 14 and 28 (Fig. 1). These four samples showed different microsatellite genotypes between the initial and recurred infections, suggestive of a newly infected parasite strain that caused recurred parasitemia after initial drug treatment.

For the 63 patients diagnosed with P. falciparum, 37 (58.7\%) showed cleared parasitemia at day 2 or 3 after treatment (Table 1; Fig. 2); 20 (31.7 \%) showed delayed clearance where residual parasitemia was detected at day 3 but cleared at day 7; and six (9.5\%) showed initial decline but recurred parasitemia after day 14 of the 
Table 1 Parasite clearance and recurred infection of $P$. falciparum and P. vivax cases in Myanmar

\begin{tabular}{|c|c|c|c|}
\hline \multicolumn{4}{|l|}{ P. falciparum } \\
\hline \multicolumn{4}{|l|}{ IDP settlement } \\
\hline & \multirow[t]{4}{*}{ Clearance time } & & No. of cases (\%) \\
\hline & & 2 days & $11(29.7)$ \\
\hline & & 3 days & $12(32.4)$ \\
\hline & & $7+$ days & $12(32.4)$ \\
\hline & \multirow[t]{2}{*}{ Recurred infection } & & $2(5.4)$ \\
\hline & & Total & 37 \\
\hline \multicolumn{4}{|l|}{ Village } \\
\hline & \multirow[t]{4}{*}{ Clearance time } & & No. of cases \\
\hline & & 2 days & $9(34.6)$ \\
\hline & & 3 days & $5(19.2)$ \\
\hline & & $7+$ days & $8(30.7)$ \\
\hline & \multirow[t]{2}{*}{ Recurred infection } & & $4(15.4)$ \\
\hline & & Total & 26 \\
\hline \multicolumn{4}{|l|}{ P. vivax } \\
\hline \multicolumn{4}{|l|}{ IDP settlement } \\
\hline & \multirow[t]{4}{*}{ Clearance time } & & No. of cases \\
\hline & & 2 days & $78(74.3)$ \\
\hline & & 3 days & $21(20)$ \\
\hline & & $7+$ days & $2(1.9)$ \\
\hline & \multirow[t]{2}{*}{ Recurred infection } & & $4(3.8)$ \\
\hline & & Total & 105 \\
\hline \multicolumn{4}{|l|}{ Village } \\
\hline & \multirow[t]{4}{*}{ Clearance time } & & No. of cases \\
\hline & & 2 days & $25(100)$ \\
\hline & & 3 days & 0 \\
\hline & & $7+$ days & 0 \\
\hline & \multirow[t]{2}{*}{ Recurred infection } & & 0 \\
\hline & & Total & 25 \\
\hline
\end{tabular}

treatment (Fig. 2). Results based on $\mathrm{PRR}_{48}$ were largely consistent with those based on day-3 positivity. All samples that were defined as fast clearance (cleared on day 2 or 3) indicated $>99 \%$ parasite clearance after $48 \mathrm{~h}$. For samples that showed delayed clearance, parasites were only reduced to $>99 \%$ after day- 3 with the exception of one sample that showed $>99 \%$ clearance at day-3 after normalization with initial parasitemia.

When we stratified our samples by age, a greater proportion of samples that displayed fast parasite clearance time were adults (23 out of 37; Additional file 1), whereas a greater proportion of samples that displayed delayed parasite clearance time belong to the younger age group (16 out of 26). Such differences, however, were not significant likely due to small sample size.
Interestingly, samples from the younger age group with delayed clearance time indicated a significantly higher initial parasitemia compared to those with fast clearance time (Fig. 3). Nonetheless, the level of initial parasitemia did not shown to be significantly different by parasite clearance time in adults.

Among the recurred infections, four showed microsatellite genotypes different from the initial infections, suggestive of a newly infected parasite strain that caused recurred parasitemia; whereas the remaining two samples showed identical genotypes. Between samples that showed fast (parasite cleared at day 2 or 3 ) and delayed (parasite observed at day3 or after) clearance of $P$. falciparum, no genetic differentiation was observed based on microsatellite loci despite that these samples were clustered by geographical sites (Fig. 4).

\section{Resistance gene polymorphisms in $P$. falciparum}

Because only two out of the 130 P. vivax samples indicated delayed parasitemia clearance, resistance gene mutation was not examined on $P$. vivax. For the $63 P$. falciparum samples that indicated varied parasite clearance time, all had the wild type genotype K76 of the pfcrt gene (Fig. 4; Additional file 2). Likewise, for pfmdr1all samples showed the wild type N86, N1042, and D1246, except for codon 184, of which approximately $50 \%$ of the patients with fast and delayed parasite clearance showed Y184 and 184 F, respectively (Fig. 5; Additional file 2). Nevertheless, based on regression analyses, mutation at this codon position was not significantly associated with delayed clearance in our samples (Additional file 3). Our qPCR data indicated that patients with delayed parasite clearance contained almost an equal proportion of single, duplicate, and more copies of the $p f m d r 1$ gene, whereas those with fast parasite clearance contained mostly two or more copies. The difference observed in pfmdr1 copy number was not shown to be significantly associated with parasite clearance time.

Amplification and sequencing of the entire pfatp 6 gene indicated polymorphisms at codons 89 and 769 , but no mutations at codons 37, 639, and 898 among the P. falciparum samples. For codon 89 , the majority of the samples $(86.7 \%)$ showed to have the wild typel 89 genotype, while the remaining eight samples (fast clearance) had the mutant $89 \mathrm{~T}$ (Fig. 5; Additional file 2). On the other hand, for codon $769,70.6 \%$ of the patients with fast parasite clearance and all of those with delayed clearance had the mutant 769A, whereas only 10 samples (patients with fast clearance) had the wild type D769 genotype (Fig. 5; Additional file 2). These mutations were shown to be not significantly associated with difference in the parasite clearance time.

For the pfimrp 1 gene, polymorphisms were detected at four codon positions (H191Y, S437A, H866N, and I876V). 


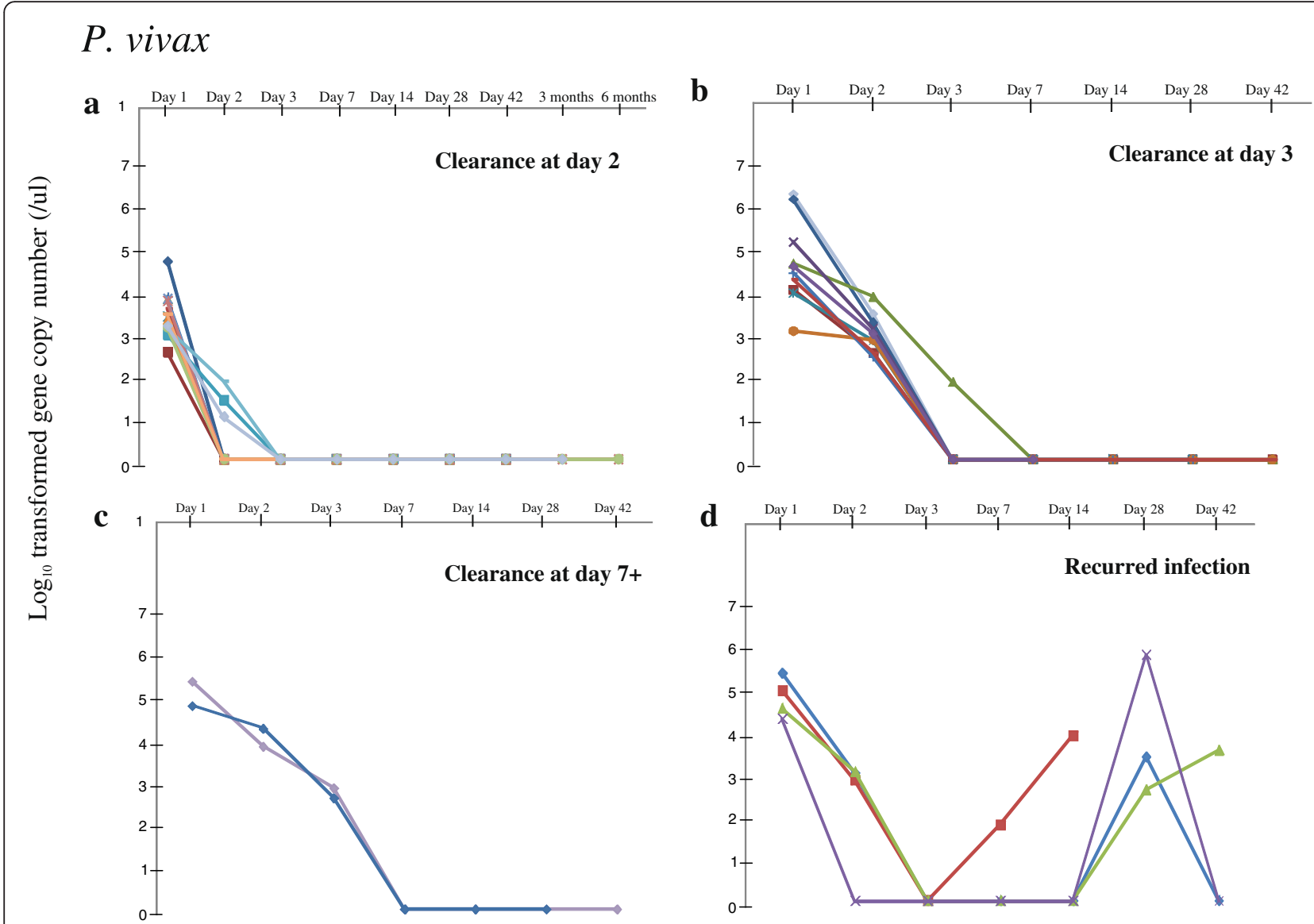

Fig. 1 Change in Plasmodium vivax parasitemia among follow-up samples collected from day-0 (the day when the patient was admitted to the hospital and sought antimalarial treatment) to up to 6-months after treatment. Samples with cleared parasitemia at day-2 a, day-3 $\mathbf{b}$, at day-7 and after $\mathbf{c}$, and with recurred parasitemia $\mathbf{d}$ were presented. For the samples that showed recurred infection, the initial and recurred genotypes were found to be different based on microsatellites, suggestive of a newly infected parasite strain that caused recurred parasitemia after initial drug treatment

The proportion of wild type and mutant at codons 191 and 437 were roughly $50 \%$, respectively, among the patients with fast and delayed parasite clearance, whereas at codons 866 and 876 over $65 \%$ and $80 \%$ of the samples showed to have the wild type respectively (Fig. 5; Additional file 2). No samples indicated any mutation at codon 1466 but wild type K1466, similar to the findings of Pirahmadi et al. [50]. Among all the detected polymorphisms, logistic regression analyses indicated significant association between the mutation in codon 876 of Pfmrp 1 and clearance time $\left(\chi^{2}=7.92\right.$, d.f. $\left.=1, P=0.005\right)$.

For the small fragment of the K13 gene, mutations were detected at the amino acid position 446, of which $66 \%$ had the wild type F and $34 \%$ had the mutant I among all samples. However, this mutation was not significantly associated with the parasite clearance time.

\section{Discussion}

In the present study, blood samples of malaria patients who received antimalarial treatment were monitored for at least 28 days. The efficacy of antimalarial therapy was interpreted by the reduction of the parasite load for these patients. Changing patterns of morphological appearances of parasite species possibly due to drug pressure or strain variation can present difficulty to quantify parasite load by microscopy [54]. Quantifying parasitemia based on qPCR provides a sensitive means in measuring samples of low or submicroscopic parasitemia particularly during antimalarial treatment [43]. However, it is noteworthy that in the present study human DNA was not amplified as internal controls for our samples. Despite that amplification was done in triplicate for each of our samples, we cannot rule out the possibility that DNA extraction or PCR errors may slightly influence the quantification of parasite DNA.

In Southeast Asia, artemisinin derivatives have been used for more than two decades as first-line malaria treatment. However, recent reports of delayed parasite clearance after artemisinin-based treatment raises concerns about the effectiveness of the drug as well as the 


\section{P. falciparum}
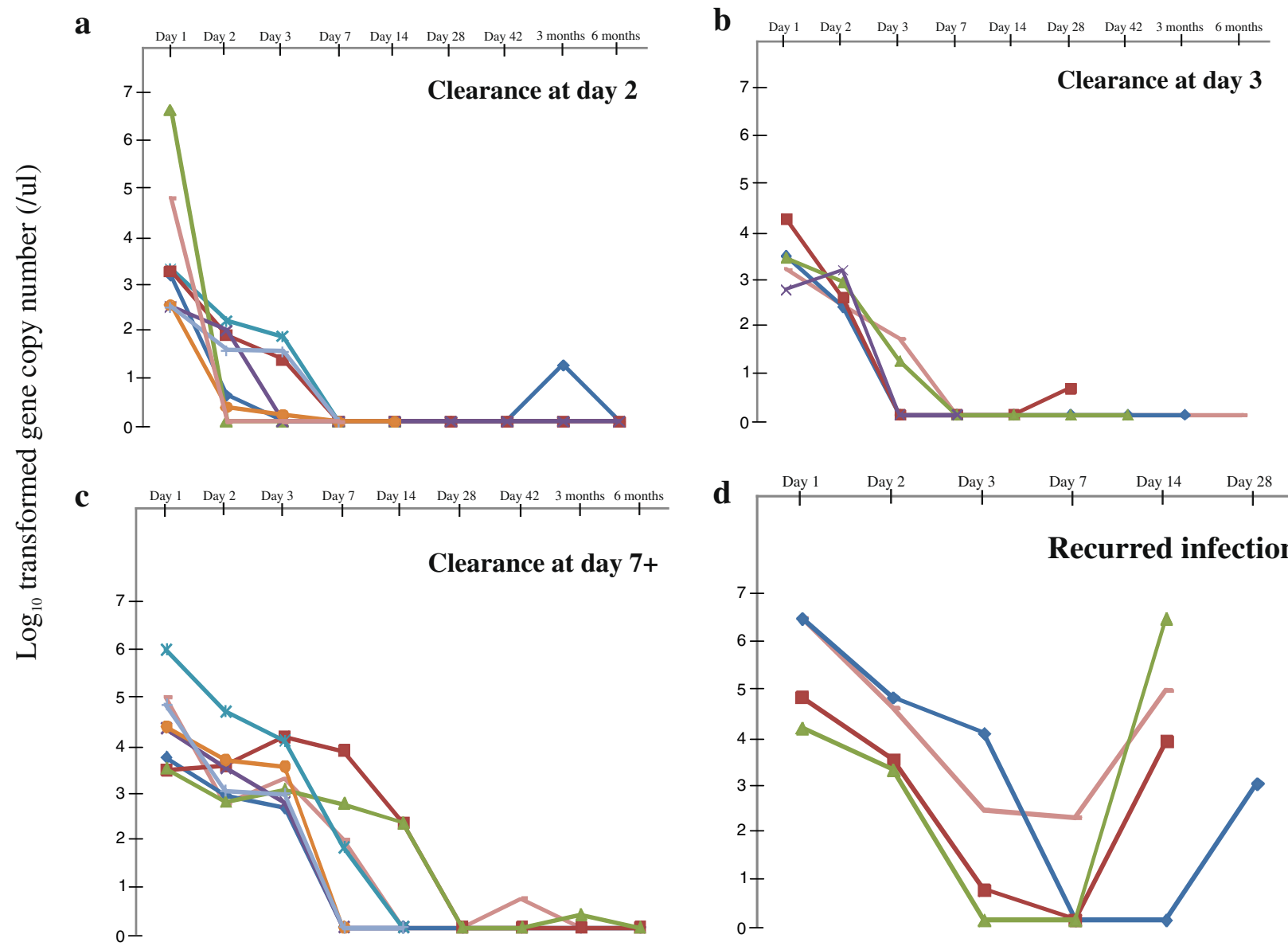

Fig. 2 Change in Plasmodium falciparum parasitemia among follow-up samples collected from day-0 (the day when the patient was admitted to the hospital and sought antimalarial treatment) to up to 6-months after treatment. Samples with cleared parasitemia at day-2 a, day-3 b, at day-7 and after $\mathbf{c}$, and with recurred parasitemia $\mathbf{d}$ were presented. For the samples that showed recurred infection, two samples showed identical microsatellite genotypes

spread of resistance especially in malaria endemic countries $[8,55,56]$. For instances, previous studies have shown delayed parasite clearance after ACT treatments in southeastern Myanmar and border area of MyanmarThailand where artemisinin has been used for several years [11, 32, 57-60]. A study by Wang et al. [61] demonstrated an overall 42-day cure rate of $100 \%$ for DP treatment of uncomplicated P. falciparum malaria at the China-Myanmar border area and a day-3 parasitepositive rate of $7 \%$. Up to $18 \%$ (13/71) of the patients showed detectable gametocytes and a large proportion of them were persistent from the first 3 days of antimalarial treatment [61]. In Thailand, parasites with delayed clearance after ACT did not show increased resistance to artemisinin compounds based on conventional in vitro experiments [8]. In Western Cambodia, there is evidence that $P$. falciparum parasites clear slowly from the blood after ACT treatment and that the variation in clearance rate is largely explained by genotypic differences observed among parasite strains [55], despite factors such as host immunity and splenic function that cannot be ruled out. Microsatellites indicated that our $P$. falciparum samples were genotypically differentiated by sites specifically between the IDP settlement and local village in Myanmar but not differentiated by parasite clearance time of the samples. Age has been shown as a factor influencing parasite clearance time [37, 62]. It is possible that higher initial parasitemia associated with multiple infections and/or weaker immunity in the younger age group could delay the parasite clearance time. This observation merits further investigation with expanded samples.

The development of resistance to antimalarial drug in a parasite is a multifactorial molecular process and more 


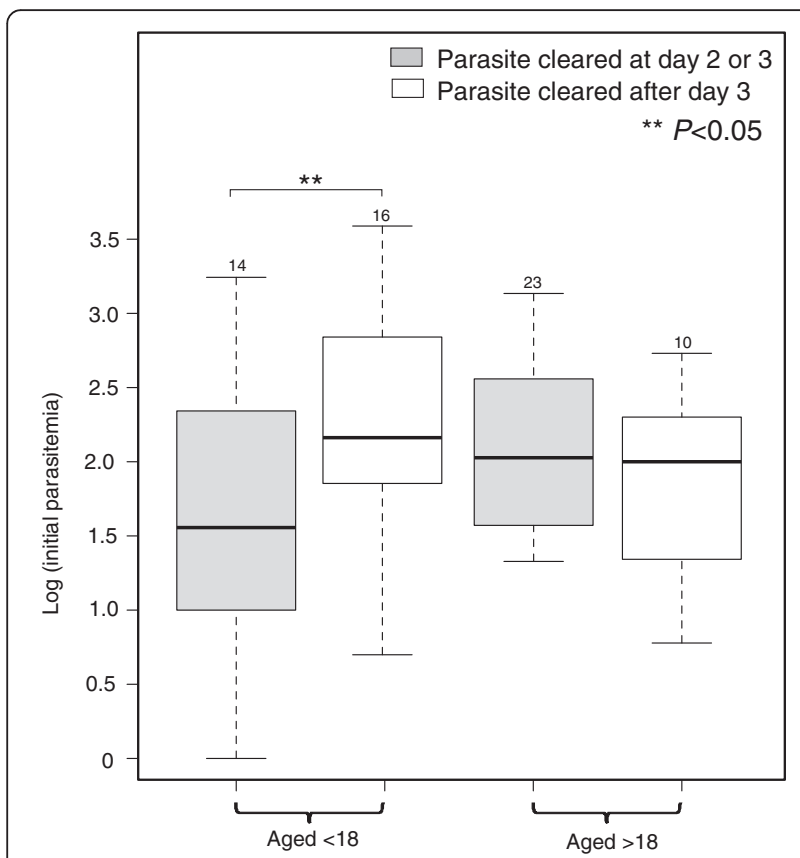

Fig. 3 Boxplot comparing initial parasitemia of $P$. falciparum samples that indicated fast (gray box; parasite cleared at day 2 or 3 ) and delayed (white box; parasite cleared after day 3) parasite clearance between two age groups (aged below and under 18). Number above bar indicates number of samples included. Asterisk indicates level of significance

than a single gene could be involved in reduced susceptibility. Various mutations in genes such as pfatp6, $p f m d r 1$ and $p f m r p 1$ have been suggested to account for ACT resistance. Recently, mutations in the Kelch-13 propeller gene were proposed to be involved in ACT resistance. In Mynamar, ACT has been used as first-line antimalarial treatment since the 1990s subsequent to decline in clinical efficacy of CQ and SP [3]. Earlier studies showed that complete withdrawal or reduced usage of CQ as first-line antimalarials can result in a decreased prevalence of pfmdr $186 \mathrm{Y}$ and pfcrt $76 \mathrm{~T}$ mutations [63, 64]. Despite our small sample size, our data agrees with this finding and reveals a dominance of wild type genotypes in both genes (except $p f m d r 1$ codon 184) that relate to $C Q$ resistance among the P. Falciparum samples. Given that $\mathrm{CQ}$ has not been used for more than a decade in Mynamar, a relaxation of selective pressure likely resulted in high susceptibility of $P$. falciparum to this drug.

The role of pfmdr1 gene mutations in artemisininbased drug resistance is unclear. Previous in vivo studies showed that mutations at codons 86 and 1246 play an important role in the resistance of $P$. falciparum to mefloquine and artemisinin [65]. In the Thai-Myanmar border region, $1226 \mathrm{Y}$ mutant was prevalent among $P$. falciparum parasites and significantly associated with in vitro response to artemisinin [30]. However, these mutations were not observed in our samples. The $184 \mathrm{~F}$ allele was reported to be associated with increased $\mathrm{IC}_{50}$ of artesunate based on in vitro study [66]. Approximately $86 \%$ of the $184 \mathrm{~F}$ allele was reported in western Cambodia where the level of MQ resistance was significant [67]. Imwong et al. [68] has also shown that $184 \mathrm{~F}$ of pfmdr1 is the only mutation associated with slow parasite clearance rates, despite the fact that such association did not persist when the results were adjusted by site. Although184F was found to be prevalent among our samples, this mutation was not significantly correlated with the parasite clearance time in the present study. Furthermore, while various studies showed that increased $p f m d r 1$ gene copy number is significantly related to a reduced sensitivity of $P$. falciparum to mefloquine, quinine, and artesunate resistance $[18,30,53,69]$,

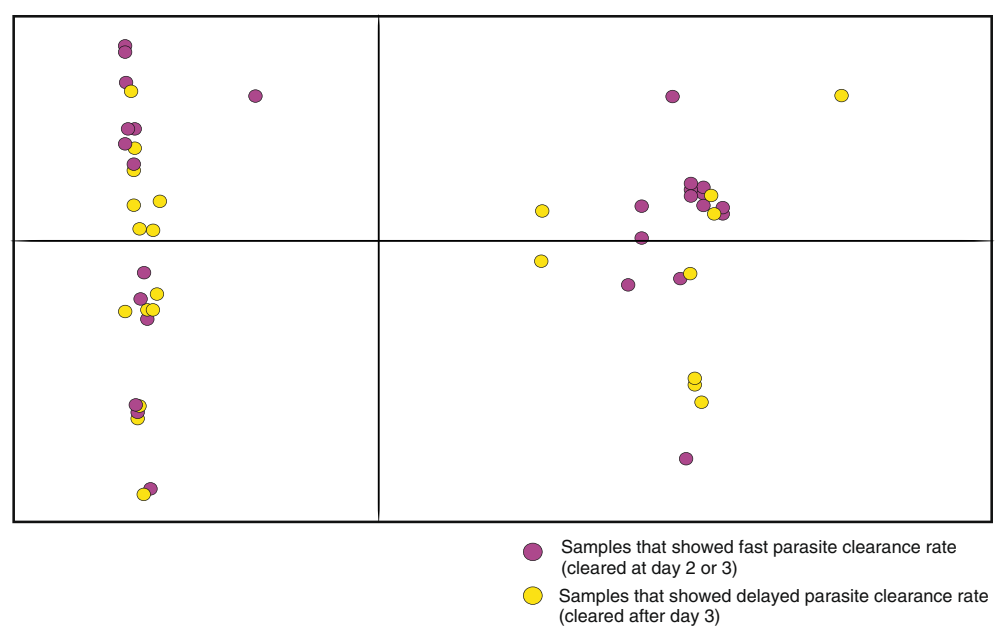

Fig. 4 Scatter plot based on Principal Component Analysis (PCA) of microsatellite data among the fast (purple color; no parasite detected at day-3) and delayed (yellow color; parasite detected after day-3) clearance samples of $P$. falciparum 


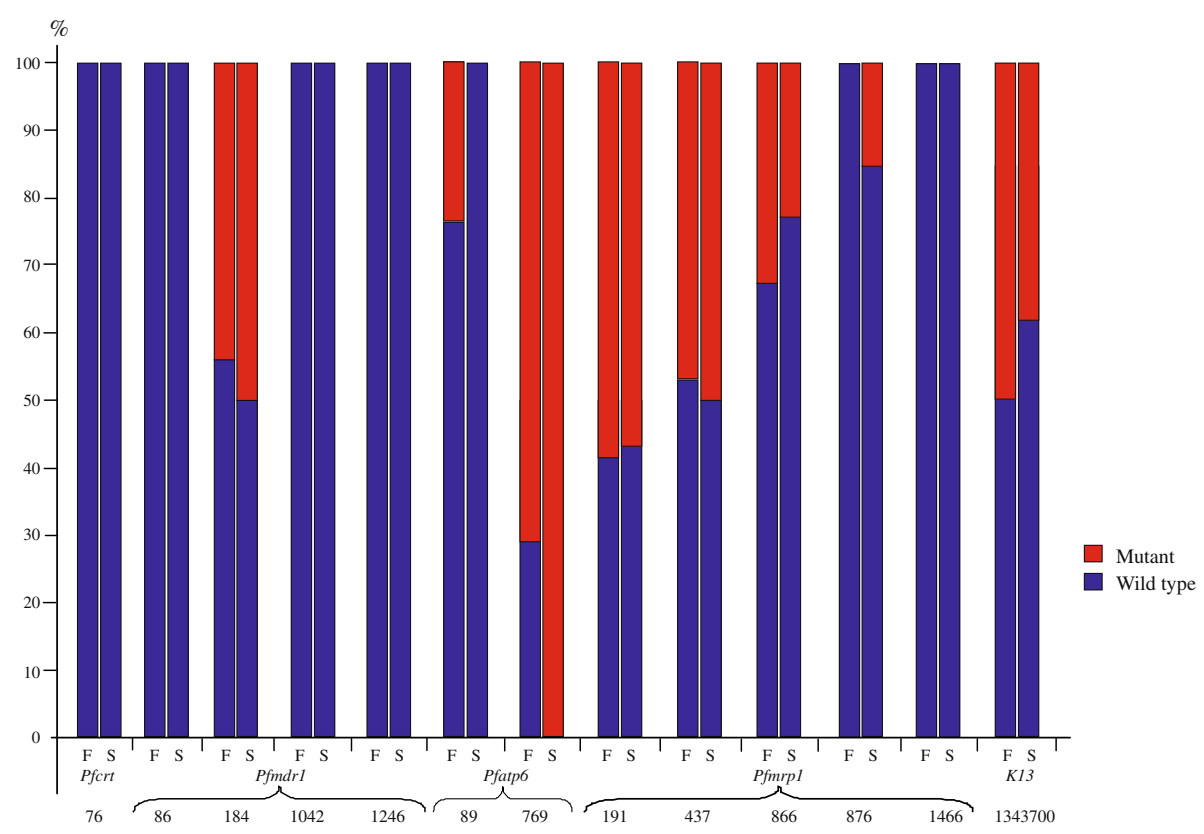

Fig. 5 Frequency of mutations in various gene codons among samples that showed fast (parasite cleared at day 2 or 3 ) and delayed (parasite cleared after day 3) clearance of $P$. falciparum. Bold denotes codon of which the mutation frequency is significantly associated with the parasite clearance time

our samples showed no significant correlation between gene copy number and parasite clearance time.

Previous studies suggested that mutations in the gene pfatp6, which encodes the sarcoplasmic and endoplasmic reticulum $\mathrm{Ca}^{2+}$-ATPase (SERCA)-type protein in $P$. falciparum may alter the parasite sensitivity to artemisinin [70]. For instances, Jambou et al. [27] reported a significant decrease in invitro sensitivity to artemether in P. falciparum isolates from French Guiana and that this reduced efficacy was associated with a S769N polymorphism in the pfatp 6 gene. Several polymorphisms have also been identified in the pfatp 6 gene including the mutations E431K and A623E in Senegal [71], I89T in Thailand [53], H243Y in Central Africa [72], T2694 in São Tomé and Principe [52], as well as R37K and A630S in Brazilian Amazon [73]. In 2008, Dahlstrom et al. [28] identified 33 single nucleotide polymorphisms (SNPs), three of which were found in a frequency higher than $5 \%$ in codons $\mathrm{H} 431 \mathrm{~K}$, N569K and A630S among the P. falciparum isolates from East and West Africa. In this study, polymorphism was detected only in codons 89 and 769. However, no significant correlation was observed between these mutations and parasite clearance time. While our small sample size may have hidden other possible mutations or underestimated the frequency of the observed mutations, it is also possible that pfatp6 does not play a key role in ACT resistance as shown in recent studies $[29,73,74]$.
Apart from the pfatp6, pfmrp1 from the ATP-binding cassette $(A B C)$ family of transporters has recently emerged as a potential genetic target for multiple drugs. The mutations in the gene pfmrpl have been shown to be associated with resistance to chloroquine, quinine, sulfadoxine/pyrimethamine and artemisinin derivatives in P. falciparum [24, 25, 66, 75-78]. Although recent studies indicated that mutations $1390 \mathrm{I}$ and $1466 \mathrm{~K}$ were associated, respectively, with artemisinin and SP resistance [78], our samples all showed wide type allele in these codon positions despite the limited sample size. These results suggest either a marked reduction of selection pressure with these antimalarials in the study area or there are other mutations that play a more vital role in determining resistance. In this study, the only mutation that was significantly associated with delayed parasite clearance is $876 \mathrm{~V}$. Although this mutation has been shown to play a significant role in changing the functionality of the protein [78] and recent studies have reported its association with in vivo ACT response $[24,30]$ as well as in vitro susceptibility to chloroquine [34], the low frequency of this mutation among our samples suggests potentially other mutations that were not examined here are responsible for delayed clearance.

A recent population study of the K13-propeller polymorphisms has shown a predominant F446I mutation in $P$. falciparum from the China-Myanmar border area [31, 32]. This mutation was shown to be equally prevalent in our patients with fast and delayed 
parasite clearance, and no association was found between its mutation and delayed parasite clearance time. The full sequence of the K13 gene will be examined on broad samples based on pyrosequencing and the frequency of other mutations will be reported elsewhere.

\section{Conclusions}

The majority of the $P$. vivax infections showed parasite clearance at day- 2 or -3 subsequent to first day drug treatment, indicative of continual effectiveness of chloroquine on P. vivax in Myanmar. By contrast, over $40 \%$ of the $P$. falciparum infections indicated parasite positivity after ACT drug treatment. This raises concern to the present antimalarial treatment of $P$. falciparum malaria in combat with the emergence and spread of ACT resistance.

\section{Ethics statement}

Scientific and ethical clearance was given by the institutional scientific and ethical review boards of Kunming Medical University, China; University of California at Irvine, USA; Pennsylvania State University, USA; and the Bureau of Health of Kachin State, Myanmar. Written informed consent/assent for study participation was obtained from all consenting heads of households or parents/guardians (for minors under age 18) and from each individual who was willing to participate in the study.

\section{Availability of data and materials}

The age distribution of patients that showed fast as well as delayed parasite clearance can be found in Additional file 1. Mutation type of the different codon positions of each sample can be found in Additional file 2. The frequency of mutations in various gene codons among the study samples can be found in Additional file 3.

\section{Additional files}

Additional file 1: Histogram showing the number of patients that indicated fast parasite clearance (cleared at day 2 or 3) as well as delayed clearance (parasite cleared after day 3) with respect to two age groups (blue: aged below 18; red: aged above 18). The level of significance was indicated. (EPS $280 \mathrm{~kb}$ )

Additional file 2: Mutation type of each of the targeted codon positions of respective genes as well as $m d r 1$ gene copy number among fast and delay clearance $P$. falciparum samples. (XLSX $15 \mathrm{~kb}$ )

Additional file 3: Frequency of mutations in various gene codons among samples that showed fast (parasite cleared at day 2 or 3) and delayed (parasite cleared after day 3 ) clearance of $P$. falciparum. Bold denotes codon of which the mutation frequency is significantly associated with the parasite clearance time. (DOCX $77 \mathrm{~kb}$ )

\section{Abbreviations}

ACT: Artemisinin Combined Therapy; atp: adenosine triphosphate; CQ: chloroquine; crt: chloroquine resistance transporter; dhfr: dihydrofolate reductase; dhps: dihydropteroate synthase; DP: dihydroartemisinin- piperaquine; GCN: gene copy number; GMS: Greater Mekong Subregion; mdr1: multi-drug resistance gene; mrp: multidrug-resistance protein; MQ: mefloquine; PCT: Parasite Clearance Time; PRR: parasite reduction ratio; qPCR: quantitative Real-Time PCR; SP: sulphadoxine and pyrimethamine.

\section{Competing interests}

The authors declare that they have no competing interests.

\section{Authors' contributions}

EL LC GY conceived and designed the experiments; JN WO EL performed the experiments and collected the data; EL GZ analyzed the data; EL JN EH wrote the paper; ZY LC GY revised and approved the manuscript before submission. All authors read and approved the final manuscript.

\section{Author's information}

Dr. Eugenia Lo is a project scientist in the Program in Public Health at University of California, Irvine. Her research focuses on molecular epidemiology and population genetics of parasite and host related to infectious disease.

\section{Acknowledgments}

The authors thank the field team for their technical assistance. We are grateful to the communities and hospitals for their support and willingness to participate in this research.

\section{Funding}

This project was funded by the National Institute of Health (Grant no. U19 Al089672). The funders have no role in study design, data collection and analysis, decision to publish or preparation of the manuscript.

\section{Author details}

${ }^{1}$ Program in Public Health, University of California at Irvine, Irvine, CA 92697-4050, USA. ²Department of Pathogen Biology and Immunology, Kunming Medical University, Kunming, China. ${ }^{3}$ Department of Entomology, Pennsylvania State University, University Park, PA, USA.

Received: 9 September 2015 Accepted: 25 March 2016

Published online: 16 April 2016

\section{References}

1. Cui L, Yan G, Sattabongkot J, Chen B, Cao Y, Fan Q, Parker D, Sirichaisinthop J, Su XZ, Yang H, Yang Z, Wang B, Zhou G. Malaria in the Greater Mekong Subregion: heterogeneity and complexity. Acta Trop. 2012;121:227-39.

2. Roper C, Pearce R, Nair S, Sharp B, Nosten F, Anderson T. Intercontinental spread of pyrimethamine-resistant malaria. Science. 2004;305:1124.

3. Mita T, Tanabe K, Kita K. Spread and evolution of Plasmodium falciparum drug resistance. Parasitol Int. 2009;58:201-9.

4. Wongsrichanalai $\mathrm{C}$, Sibley $\mathrm{CH}$. Fighting drug-resistant Plasmodium falciparum: the challenge of artemisinin resistance. Clin Microbiol Infect. 2013;19:908-16.

5. Beshir KB, Sutherland CJ, Sawa P, Drakeley CJ, Okell L, Mweresa CK, Omar SA, Shekalaghe SA, Kaur H, Ndaro A, Chilongola J, Schallig HDFH, Sauerwein RW, Hallett RL, Bousema T. Residual Plasmodium falciparum parasitemia in Kenyan children after artemisinin-combination therapy is associated with increased transmission to mosquitoes and parasite recurrence. J Infect Dis. 2008;2013:2017-24.

6. White NJ. Qinghaosu (artemisinin): the price of success. Science. 2008;320: 330-4.

7. Denis MB, Tsuyuoka R, Poravuth Y, Narann TS, Seila S, Lim C, Incardona S, Lim P, Sem R, Socheat D, Christophel EM, Ringwald P. Surveillance of the efficacy of artesunate and mefloquine combination for the treatment of uncomplicated falciparum malaria in Cambodia. Trop Med Int Health. 2006; 11:1360-6.

8. Dondorp AM, Nosten F, Yi P, Das D, Phyo AP, Tarning J, Lwin KM, Ariey F, Hanpithakpong W, Lee SJ, Ringwald P, Silamut K, Imwong M, Chotivanich K, Lim P, Herdman T, An SS, Yeung S, Singhasivanon P, Day NPJ, Lindegardh $\mathrm{N}$, Socheat D, White NJ. Artemisinin resistance in Plasmodium falciparum malaria. N Engl J Med. 2009;361:455-67.

9. Amaratunga C, Sreng S, Suon S, Phelps ES, Stepniewska K, Lim P, Zhou C, Mao S, Anderson JM, Lindegardh N, Jiang H, Song J, Su XZ, White NJ, Dodorp AM, Anderson TJ, Fay MP, Mu J, Duong S, Fairhurst RM. Artemisinin- 
resistant Plasmodium falciparum in Pursat province, western Cambodia: a parasite clearance rate study. Lancet Infect Dis. 2012;12:851-8.

10. Wongsrichanalai C, Meshnick SR. Declining artesunate-mefloquine efficacy against falciparum malaria on the Cambodia-Thailand border. Emerg Infect Dis. 2008;14:716-9.

11. Carrara VI, Zwang J, Ashley EA, Price RN, Stepniewska K, Barends M, Brockman A, Anderson T, McGready R, Phaiphun L, Proux S, van Vugt M, Hutagalung R, Lwin KM, Phyo AP, Preechapornkul P, Imwong M, Pukrittayamakee $S$, Singhasivanon $P$, White NJ, Nosten F. Changes in the treatment responses to artesunate-mefloquine on the northwestern border of Thailand during 13 years of continuous deployment. PLoS One. 2009:4:e4551.

12. White NJ. The parasite clearance curve. Malar J. 2011;10:278

13. Djimde A, Doumbo OK, Cortese JF, Kayentao K, Doumbo S, Diourte Y, Dicko A, Su X-Z, Noruma T, Fidock DA, Wellems TE, Plowe CV. A molecular marker for chloroquine resistant falciparum malaria. N Engl J Med. 2001;344:257-63.

14. Sidhu $A B$, Verdier-Pinard D, Fidock DA. Chloroquine resistance in Plasmodium falciparum malaria parasites conferred by pfcrt mutations. Science. 2002;298: 210-3.

15. Chen N, Kyle DE, Pasay C, Fowler EV, Baker J, Peters JM, Cheng Q. Pfcrt allelic types with two novel amino acid mutations in chloroquine resistant Plasmodium falciparum isolates from the Philippines. Antimicrob Agents Chemother. 2003:47:3500-5.

16. Reed MB, Saliba KJ, Caruana SR, Kirk K, Cowman AF. Pgh1 modulates sensitivity and resistance to multiple antimalarials in Plasmodium falciparum. Nature. 2000:403:906-9.

17. Mu J, Ferdig MT, Feng X, Joy DA, Duan J, Furuya T, Subramanian G, Aravind L, Cooper RA, Wootton JC, Xiong M, Su XZ. Multiple transporters associated with malaria parasite responses to chloroquine and quinine. Mol Microbiol. 2003:49:977-89.

18. Phompradit P, Muhamed P, Wisedpanichkij R, Chaijaroenkul W, Na-Bangchang K. Four years' monitoring of in vitro sensitivity and candidate molecular markers of resistance of Plasmodium falciparum to artesunate-mefloquine combination in the Thai-Myanmar border. Malar J. 2014;13:23.

19. Cowman AF, Morry MJ, Biggs BA, Cross GA, Foote SJ. Amino acid changes linked to pyrimethamine resistance in the dihydrofolate reductasethymidylate synthase gene of Plasmodium falciparum. Proc Natl Acad Sci U S A. 1988:85:9109-13.

20. Triglia T, Menting JG, Wilson C, Cowman AF. Mutations in dihydropteroate synthase are responsible for sulfone and sulfonamide resistance in Plasmodium falciparum. Proc Natl Acad Sci U S A. 1997;94:13944-9.

21. Plowe CV, Kublin JG, Doumbo OK. Plasmodium falciparum dihydrofolate reductase and dihydropteroate synthase mutations: epidemiology and role in clinical resistance to antifolates. Drug Resist Updates. 1998;1:389-96.

22. Zhang Y, Yan H, Wei G, Han S, Huang Y, Zhang Q, Pan W. Distinctive origin and spread route of pyrimethamine-resistant Plasmodium falciparum in Southern China. Anitmicrob Agents Chemother. 2013;58:237.

23. Sanchez CP, Dave A, Stein WD, Lanzer M. Transporters as mediators of drug resistance in Plasmodium falciparum. Int J Parasitol. 2010;40:1109-18.

24. Dahlström S, Ferreira PE, Veiga Ml, Sedighi N, Wiklund L, Martensson A, Farnert A, Sisowath C, Osorio L, Darban H, Andersson B, Kaneko A, Conseil G, Bjorkman A, Gil JP. Plasmodium falciparum multidrug resistance protein 1 and artemisinin-based combination therapy in Africa. J Infect Dis. 2009;200: 1456-64.

25. Gupta B, Xu S, Wang Z, Sun L, Miao J, Cui L, Yang Z. Plasmodium falciparum multidrug resistance protein 1 (pfmrp1)gene and its association with in vitro drug susceptibility of parasite isolates from north-east Myanmar. J Antimicrob Chemother. 2014;69:2110-7.

26. Uhlemann AC, Cameron A, Eckstein-Ludwig U, Fischbarg J, Iserovich $P$, Zuniga FA, East M, Lee A, Brady L, Haynes RK, Krishna S. A single amino acid residue can determine the sensitivity of SERCAs to artemisinins. Nature Struct Mol Biol. 2005;12:628-9.

27. Jambou R, Legrand E, Niang M, Khim N, Lim P, Volney B, Ekala MT, Bouchier C, Esterre P, Fandeur T, Mercereau-Puijalon O. Resistance of Plasmodium falciparum field isolates to in-vitro artemether and point mutations of the SERCA-type PfATPase6. Lancet. 2005;366:1960-3.

28. Dahlström S, Veiga Ml, Ferreira P, Mårtensson A, Kaneko A, Andersson B, Björkman A, Gil JP. Diversity of the sarco/endoplasmic reticulum $\mathrm{Ca}(2+)$ -ATPase orthologue of Plasmodium falciparum (PfATP6). Infect Genet Evol. 2008;8:340-5.
29. Phompradit P, Wisedpanichkij R, Muhamad P, Chaijaroenkul W, Na-Bangchang K. Molecular analysis of pfatp6 and pfmdr1 polymorphisms and their association with in vitro sensitivity in Plasmodium falciparum isolates from the Thai-Myanmar border. Acta Trop. 2011;120:130-5.

30. Veiga MI, Ferreira PE, Jörnhagen L, Malmberg M, Kone A, Schmidt BA, Petzold M, Björkman A, Nosten F, Gil JP. Novel polymorphisms in Plasmodium falciparum $\mathrm{ABC}$ transporter genes are associated with major ACT antimalarial drug resistance. PLoS One. 2011;6:e20212.

31. Wang Z, Shrestha S, Li X, Miao J, Yuan L, Cabrera M, Grube C, Yang Z, Cui L. Prevalence of K13-propeller polymorphisms in Plasmodium falciparum from China-Myanmar border in 2007-2012. Malar J. 2015;14:168.

32. Tun KM, Imwong M, Lwin KM, Win AA, Hlaing TM, Hlaing T, Lin K, Kyaw MP, Plewes K, Faiz MA, Dhorda M, Cheah PY, Pukrittayakamee S, Ashley EA, Anderson TJC, Nair S, McDew-White M, Flegg JA, Grist EPM, Guerin P, Maude RJ, Smithuis F, Dondorp AM, Day NPJ, Nosten F, White NJ, Woodrow CJ. Spread of artemisinin-resistant Plasmodium falciparum in Myanmar: a cross-sectional survey of the K13 molecular marker. Lancet Infect Dis. 2015:15:415-21.

33. Wang Z, Parker D, Meng H, Wu L, Li J, Zhao Z, Zhang R, Fan Q, Wang H, Cui L, Yang Z. In vitro sensitivity of Plasmodium falciparum from ChinaMyanmar border area to major ACT drugs and polymorphisms in potential target genes. PLoS One. 2012;7:e30927.

34. Hao M, Jia D, Li Q, He Y, Yuan L, Xu S, Chen K, Wu J, Shen L, Sun L, Zhao H, Yang Z, Cui L. In vitro sensitivities of Plasmodium falciparum isolates from the China-Myanmar border to piperaquine and association with polymorphisms in candidate genes. Antimicrob Agents Chemother. 2013;57:1723-9.

35. Beshir KB, Hallett RL, Eziefula AC, Bailey R, Watson J, Wright SG, Chiodini PL, Polley SD, Sutherland CJ. Measuring the efficacy of anti-malarial drugs in vivo: quantitative PCR measurement of parasite clearance. Malar J. 2010;9:312.

36. Bereczky S, Martensson A, Gil JP. Short report: Rapid DNA extraction from archive blood spots on filter paper for genotyping of Plasmodium falciparum. Am J Trop Med Hyg. 2005;72:249-51.

37. Maiga AW, Fofana B, Sagara I, Dembele D, Dara A, Traore OB, Toure S, Sanogo K, Dama S, Sidibe B, Kone A, Thera MA, Plowe CV, Doumbo OK, Djimde AA. No evidence of delayed parasite clearance after oral artesunate treatment of uncomplicated falciparum malaria in Mali. Am J Trop Med Hyg. 2012;87:23-8

38. Muhindo MK, Kakuru A, Jagannathan P, Talisuna A, Osilo E, Orukan F, Arinaitwe E, Tappero JW, Kaharuza F, Kamya MR, Dorsey G. Early parasite clearance following artemisinin-based combination therapy among Ugandan children with uncomplicated Plasmodium falciparum malaria. Malar J. 2014:13:32.

39. Thriemer K, Nguyen VH, Rosanas-Urgell A, Phuc BQ, Ha DM, Pockele E, Guetens P, Nguyen W, Duong TT, Amambua-Ngwa A, Alessandro U D', Erhart A. Delayed parasite clearance after treatment with dihydroartemisininpiperaquine in Plasmodium falciparum malaria patients in central Vietnam. Antimicrob Agents Chemother. 2014:58:7049-55.

40. Noedl H, Se Y, Schaecher K, Smith BL, Socheat D, Fukuda MM. Evidence of artemisinin-resistant malaria in Western Cambodia. N Engl J Med. 2008;359: 2619-20.

41. Vijaykadga S, Alker AP, Satimai W, MacArthur JR, Meshnick SR, Wongsrichanalai C. Delayed Plasmodium falciparum clearance following artesunate-mefloquine combination therapy in Thailand, 1997-2007. Malar J. 2012;11:296.

42. Nkhoma SC, Stepniewska K, Nair S, Phyo AP, McGready R, Nosten F, Anderson TJC. Genetic evaluation of the performance of malaria parasite clearance rate metrics. J Infect Dis. 2013;208:346-50.

43. Rougemont M, Van Saanen M, Sahli R, Hinrikson HP, Bille J, Jaton K. Detection of four Plasmodium species in blood from humans by 18 S rRNA gene subunit-based and species-specific real-time PCR assays. J Clin Microbiol. 2004;42:5636-43.

44. Anderson TJC, Su XZ, Bockarie M, Lagog M, Day KP. Twelve microsatellite markers for characterization of Plasmodium falciparum from finger-prick blood samples. Parasitology. 1999;119:113-25.

45. Su XZ, Gerdig MT, Huang Y, Huynh CQ, Liu A, You J, Wootton JC, Wellems, TE. A genetic map and recombination parameters of the human malaria parasite Plasmodium falciparum. Science. 1999;286:1351-3.

46. Zhang GQ, Guan YY, Sheng HH, Zheng B, Wu S, Xiao HS, Tang LH. Multiplex PCR and oligonucleotide microarray for detection of single-nucleotide 
polymorphisms associated with Plasmodium falciparum drug resistance. J Clin Microbiol. 2008;46:2167-74.

47. Fidock DA, Nomura T, Talley AK, Cooper RA, Dzekunov SM, Ferdig MT, Ursos LM, Sidhu AB, Naude B, Deitsch KW, Su XZ, Wootton JC, Roepe PD, Wellems TE. Mutations in the Plasmodium falciparum digestive vacuole transmembrane protein PfCRT and evidence for their role in chloroquine resistance. Mol Cell. 2000;6:861-71.

48. Duraisingh MT, Jones P, Sambou I, von Seidlein L, Pinder M, Warhurst DC. The tyrosine-86 allele of the pfmdr1 gene of Plasmodium falciparum is associated with increased sensitivity to the anti-malarials mefloquine and artemisinin. Mol Biochem Parasitol. 2000;108:13-23.

49. Ferreira ID, Martinelli A, Rodrigues LA, do Carmo EL, do Rosario VE, Povoa MM, Cravo P. Plasmodium falciparum from para state (Brazil) shows satisfactory in vitro response to artemisinin derivatives and absence of the S769N mutation in the SERCA-type PfATPase6. Trop Med Int Health. 2008;13:199-207.

50. Pirahmadi S, Zakeri S, Afsharpad M, Djadid ND. Mutation analysis in pfmdr1 and pfmrp1 as potential candidate genes for artemisinin resistance in Plasmodium falciparum clinical isolates 4 years after implementation of artemisinin combination therapy in Iran. Infect Genet Evol. 2013;14:327-34.

51. Happi $C T$, Gbotosho GO, Folarin OA, Sowunmi A, Hudson T, O'Neil M, Milhous W, Wirth DF, Oduola AMJ. Selection of Plasmodium falciparum multidrug resistance gene 1 alleles in asexual stages and gametocytes by artemether-lumefantrine in Nigerian children with uncomplicated falciparum malaria. Antimicrob Agents Chemother. 2009:53:888-95.

52. Ferreira I, do Rosário VE, Cravo P. Real-time quantitative PCR with SYBR Green I detection for estimating copy numbers of nine drug resistance candidate genes in Plasmodium falciparum. Malar J. 2006;5:1.

53. Price RN, Uhlemann A-C, Brockman A, McGready R, Ashley E, Phaipun L, Patel R, Laing K, Looareesuwan S, White NJ, Nosten F, Krishna S. Mefloquineresistance in Plasmodium falciparum and increased pfmdr 1 gene copy number. Lancet. 2004;364:438-47.

54. Moody A. Rapid diagnostic tests for malaria parasites. Clin Microbiol Rev. 2002;15:66-78.

55. Anderson TJC, Nair S, Nkhoma S, Williams JT, Imwong M, Yi P, Socheat D, Das D, Chotivanich K, Day NPJ, White NJ, Dondorp AM. High heritability of malaria parasite clearance rate indicates a genetic basis for artemisinin resistance in western Cambodia. J Infect Dis. 2010;201:1326-30.

56. Pukrittayakamee $S$, Chantra A, Simpson JA, Vanijanonta S, Clemens R, Looareesuwan S, White NJ. Therapeutic responses to different antimalarial drugs in vivax malaria. Antimicrob Agents Chemother. 2000;44:1680-1685.

57. Phyo PA, Nkhoma S, Stepniewska K, Ashley EA, Nair S, McGready R, Moo C Al-Saai S, Dondorp AM, Lwin KM, Singhasivanon P, Day NPJ, White NJ, Anderson TJC, Nosten F. Emergence of artemisinin-resistant malaria on the western border of Thailand: a longitudinal study. Lancet. 2012;379:960-6.

58. Kyaw MP, Nyunt MH, Chit K, Aye MM, Aye KH, Aye MM, Lindegardh N, Tarning J, Imwong M, Jacob CG, Rasmussen C, Perin J, Ringwald P, Nyunt MM. Reduced susceptibility of Plasmodium falciparum to artesunate in Southern Myanmar. PLoS One. 2013;8:e57689.

59. Busto MD, Wongsrichanalai C, Delacollette C, Burkholder B. Monitoring antimalarial drug efficacy in the Greater Mekong Subregion: an overview of in vivo results from 2008 to 2010. Southeast Asian J Trop Med Public Health. 2013:44:201-30.

60. Na-Bangchang K, Ruengweerayut R, Mahamad P, Ruengweerayut K, Chaijaroenkul W. Declining in efficacy of a three-day combination regimen of mefloquine-artesunate in a multi-drug resistance area along the Thai-Myanmar border. Malar J. 2010;9:273.

61. Wang Y, Yang Z, Yuan L, Zhou G, Parker D, Lee MC, Yan GY, Fan Q, Xiao YP, Cao Y, Cui L. Clinical efficacy of dihydroartemisinin-piperaquine for the treatment of uncomplicated Plasmodium falciparum malaria at the China-Myanmar border. Am J Trop Med Hyg. 2015;93:577-83.

62. Ndour PA, Lopera-Mesa TM, Diakité SAS, Chiang S, Mouri O, Roussel C, Jauréguiberry S, Biligui S, Kendjo E, Claessens A, Ciceron L, Mazier D, Thellier M, Diakité M, Fairhurst RM, Buffet PA. Plasmodium falciparum clearance is rapid and pitting independent in immune Malian children treated with artesunate for malaria. J Infect Dis. 2014;211:290-297.

63. Kublin JG, Cortese JF, Njunju EM, Mukadam RAG, Wirima JJ, Kazembe PN, Djimde AA, Kouriba B, Taylor TE, Plowe CV. Reemergence of chloroquinesensitive Plasmodium falciparum malaria after cessation of chloroquine use in Malawi. J Infect Dis. 2003;187:1870-5.
64. Raman J, Mauff K, Muianga P, Mussa A, Maharaj R, Barnes KI. Five years of antimalarial resistance marker surveillance in Gaza Province, Mozambique, following artemisinin-based combination therapy roll out. PLoS One. 2011;6: e25992.

65. Sidhu AB, Valderramos SG, Fidock DA. Pfmdr1 mutations contribute to quinine resistance and enhance mefloquine and artemisinin sensitivity yin Plasmodium falciparum. Mol Microbiol. 2005;57:913-26.

66. Anderson TJC, Nair S, Sudimack D, Williams JT, Mayxay M, Newton PN, Guthmann JP, Smithuis FM, Hien TT, van den Broek IVF, White NJ, Nosten F. Geographical distribution of selected and putatively neutral SNPs in Southeast Asian malaria parasites. Mol Biol Evol. 2005;22:2362-74.

67. Vinayak S, Alam MT, Sem R, Shah NK, Susanti Al, Lim P, Muth S, Maguire JD, Rogers WO, Fandeur T, Barnwell JW, Escalante AA, Wongsrichanalai C, Ariey F, Meshnick SR, Udhayakumar V. Multiple genetic backgrounds of the amplified Plasmodium falciparum multidrug resistance ( $\mathrm{pfm} d \mathrm{r} 1)$ gene and selective sweep of $184 \mathrm{~F}$ mutation in Cambodia. J Infect Dis. 2010;201:1551-60.

68. Imwong M, Dondorp AM, Nosten F, Yi P, Mungthin M, Hanchana S, Das D, Phyo AP, Lwin KM, Pukrittayakamee S, Lee SJ, Saisung S, Koecharoen K, Nguon C, Day NPJ, Socheat D, White NJ. Exploring the contribution of candidate genes to artemisinin resistance in Plasmodium falciparum. Antimicrobiol Agents Chemother. 2010;54:2886-92.

69. Price RN, Uhlemann AC, Van-Vugt M, Brockman A, Hutagalung R, Nair S, Nash D, Singhasivanon P, Anderson TJC, Krishna S, White NJ, Nosten F. Molecular and pharmacological determinants of the therapeutic response to artemether-lumefantrine in multidrug-resistant Plasmodium falciparum malaria. Clin Infect Dis. 2006:42:1570-7.

70. Eckstein-Ludwig U, Webb RJ, van Goethem IDA, East JM, Lee AG, Kimura M, O'Neill PM, Bray PG, Ward SA, Krishna S. Artemisinins target the SERCA of Plasmodium falciparum. Nature. 2003;424:957-61.

71. Pillai DR, Lau R, Khairnar K, Lepore R, Via A, Staines HM, Krishna S. Artemether resistance in vitro is linked to mutations in PfATP6 that also interact with mutations in PFMDR1 in travellers returning with Plasmodium falciparum infections. Malar J. 2012;11:131.

72. Cojean S, Hubert V, Le Bras J, Durand R. Resistance to dihydroartemisinin. Emerg Infect Dis. 2006;12:1798-9.

73. Brasil LW, Areas ALL, Melo GC, Oliveira CMC, Alecrim MGC, Lacerda MVG, O'Brien C, Oelemann WMR, Zalis MG. Pfatp6 molecular profile of Plasmodium falciparum isolates in the western Brazilian Amazon. Malar J. 2012;11:111.

74. Miao M, Wang Z, Yang Z, Yuan L, Parker DM, Putaporntip C, Jongwutiwes S, Xangsayarath P, Pongvongsa T, Moji H, Troug TD, Abe T, Nakazawa S, Cui L. Genetic diversity and lack of artemisinin selection signature on the Plasmodium falciparum ATP6 in the Greater Mekong Subregion. PLoS One. 2013;8:e59192.

75. Gómez-Saladin E, Fryaufl DJ, Taylor WR, Laksana BS, Susanti Al, Subianto PB, Richie TL. Plasmodium falciparum mdr1 mutations and in vivo chloroquine resistance in Indonesia. Am J Trop Med Hyg. 1999;61:240-244.

76. Ursing J, Zakeri S, Gil J, Bjorkman A. Quinoline resistance associated polymorphisms in the pfert, pfmdr1 and pfmrp genes of Plasmodium falciparum in Iran. Acta Trop. 2006;97:352-6.

77. Raj DK, Mu J, Jiang H, Kabat J, Singh S, Sullivan M, Fay MP, McCutchan TF, Su X. Disruption of a Plasmodium falciparum multidrug resistance-associated protein (PFMRP) alters its fitness and transport of antimalarial drugs and glutathione. J Biol Chem. 2009;284:7687-96.

78. Dahlström S, Veiga MI, Björkman A, Gil JP. Polymorphism in PfMRP1 (Plasmodium falciparum multidrug resistance protein 1) amino acid 1466 associated with resistance to Sulfadoxine-Pyrimethamine treatment. Antimicrob Agents Ch. 2009;53:2553-6. 